\title{
PERANCANGAN IDENTITAS VISUAL DESTINASI WISATA KAWASAN TELUK YOUTEFA KOTA JAYAPURA
}

\author{
Anita Karunia, Alimuddin, Nurabdiansyah \\ Desain Komunikasi Visual Fakultas Seni dan Desain Universitas Negeri makassar \\ anitakarunia27@gmail.com \\ alimuddin185@gmail.com \\ nurabdiansyah@unm.ac.id
}

\begin{abstract}
ABSTRAK
Perancangan ini bertujuan untuk menciptakan identitas visual baru yang menarik, konsisten dan sesuai dengan citra yang ingin dibangun Teluk Youtefa sebagai salah satu cara dalam pengembangan destinasi wisata di Kota Jayapura serta diterapkan pada graphic standard manual, stationery, dan gifts/merchandise agar dapat digunakan sebagai media identifikasi media promosi wisata. Data yang digali dalam penelitian ini mencakup teori desain terkait merancang logo serta teori warna, tipografi, brand, branding, identitas visual, brand awareness, serta data teluk youtefa berupa pedoman wawancara dan pedoman observasi. Data diperoleh diteliti menggunakan metode kualitatif, analisis SWOT, dan analisis STP. Logo dari Teluk Youtefa menampilkan visualisasi yang memperkenalkan nilai budaya dan keindahan alam kepada para wisatawannya, oleh karena itu identitas visual di desain agar memiliki kesan menyenangkan, dan tidak terlepas dari unsur alam dan budaya suku tobati dan enggros. Hasil perancangan identitas visual ini adalah logo dengan menggunakan media utama berupaGraphic Standard manual sebagai buku panduan yang berisi aturan serta penggunaan identitas visual Youtefa dan mencakup logo, warna dan tipografi, juga penerapannya pada media. Logo dari hasil Perancangan Identitas Visual Kawasan Teluk Youtefa kemudian diaplikasikan ke dalam media pendukung sebagai media promosi, media komunikasi pendukung terdiri dari Stationary dan Gift/ Merchandise.
\end{abstract}

Kata Kunci: Branding, Visual Identity, Design, Logo, Kawasan Teluk Youtefa.

\begin{abstract}
This Design aims to make a new visual identity that is interesting, consistent and in accordance with the image that Youtefa Bay wants to build as one of the ways in developing tourist destinations in Jayapura City and applied to graphic standard manuals, stationery, and gifts / merchandise to be used as media identification of tourism promotion media. The data unearthed in this study included design theories related to logo design and color theory, typography, brand, branding, visual identity, brand awareness, and Youtefa bay data in the form of interview guidelines and observation guidelines. The data obtained were examined using qualitative methods, SWOT analysis, and STP analysis. The logo of Youtefa Bay displays a visualization that introduces cultural values and natural beauty to the tourists, therefore visual identity is designed to have a pleasant impression, and is inseparable from the natural and cultural elements of the Tobati and Enggros tribes. The design result of this visual identity is a logo that using main media in the form of a Graphic Standard Manual manual as a guide that contains the rules and the using of Youtefa's visual identity and includes logos, colors and typography, as well as its application to the media. The logo of the Youtefa Bay Regional Visual Identity Design results was then applied to supporting media as promotional media, supporting communication media consisting of stationary and Gift/Merchandise.
\end{abstract}

Keywords: Branding, Visual Identity, Design, Logo, Kawasan Teluk Youtefa. 


\section{PENDAHULUAN}

Papua adalah sebuah provinsi di Indonesia yang terletak di pulau Nugini bagian barat atau West New Guinea. Papua dibagi menjadi dua provinsi oleh pemerintah Indonesia yaitu Papua Barat dan Papua. (Masdalia, 2018: 13). Jayapura adalah sebuah kota yang sekaligus menjadi ibu kota Provinsi Papua, terletak di bagian paling timur Indonesia. Selain menawarkan keunikan budaya, Kota Jayapura juga memiliki keindahan alam yang menakjubkan. Salah satunya dapat dilihat di Taman Wisata Alam Teluk Youtefa.

Taman Wisata Alam Teluk Youtefa terhampar di wilayah garis pantai kota Jayapura yang terletak di teluk kecil yang berada di dalam teluk Yos Sudarso. Kawasan Teluk Youtefa ini memiliki suasana yang tenang dan asri serta kawasan tempat wisata ini terdapat hutan mangrove, hutan sagu dan area perbukitan dengan ketinggian maksimal $25 \mathrm{mdpl}$. Selain ditumbuhi vegetasi bakau dan tumbuhan lainnya, kawasan ini juga menjadi tempat tinggal beberapa jenis satwa seperti burung raja udang, nuri merah kepala hitam, dan kera ekor panjang. Teluk Youtefa menawarkan pesona wisata alam dua sisi, baik di air maupun daratan. Terdapat pantai sekaligus gunung yang diselimuti pepohonan hijau nan asri. Salah satunya adalah Pantai Hamadi. Terbentang luas sepanjang dua kilometer. Tidak jauh dari pantai hamadi terdapat Gunung Mher yang sangat cantik. Berdiri megah, gunung yang satu ini memiliki goa yang sangat keramat dan suci, Goa Mher. Goa ini menjadi asal suku Tobati dan Enggros yang hingga kini mendiami Teluk Youtefa, masih dikawasan teluk Youtefa terdapat Tanjung Kaswari pantai dengan deretan pohon cemara yang sejuk dan cantik dengan bebatuan karang (Wisata Papua,2016)

Konsep wisata dengan menggabungkan unsur budaya, sejarah dan hiburan dan alam membuat tempat wisata ini memiliki potensi yang tinggi sebagai destinasi wisata di Kota Jayapura, dan harganya yang terjangkau juga membuat tempat wisata ini sangat cocok untuk dijadikan pilihan berekreasi bersama keluarga untuk refreshing.

Namun tidak banyak yang tahu ternyata di Kota Jayapura juga memiliki tempat-tempat yang tidak kalah indah untuk dijadikan alternatif liburan. Saat ini, Kota Jayapura belum seterkenal tujuan wisata lain di Papua seperti Raja Ampat, padahal Kota Jayapura juga punya pesona alam yang tidak kalah dengan Raja Ampat di Papua Barat. Serta potensi tersebut belum dikenal luas karena tidak didukung dengan pengelolaan identitas visual yang baik. Berdasarkan observasi lapangan secara langsung, identitas visual yang dimiliki Kawasan Teluk Youtefa belum konsisten. Hal tersebut terlihat dari tidak adanya logo atau identitas yang bisa membuat wisatawan tertarik atau tau tentang wisata tersebut. pintu masuk, dan sign system tidak terintegrasi dan tidak memiliki satu kesatuan yang utuh yang sesuai dengan citra Teluk Youtefa. Hal tersebut menyebabkan identitas visual brand menjadi susah diingat dan dikenali.

Brand awarness dan pengakuan akan sebuah brand dapat lebih mudah dicapai dengan adanya identitas visual yang gampang diingat dan langsung dikenali (Wheeler, 2013 : 25). Kotler dan Waldemar (2010: 20) juga mengatakan bahwa rendahnya brand awareness dapat disebabkan oleh beberapa faktor penting yang salah satunya adalah karena kurang tepatnya penggunaan brand identity sehingga belum dapat menarik perhatian konsumen (Tanuatmadja, 2014: 2). Visual brand identity sangatlah penting keberadaanya, terutama sebagai sarana untuk mengkomunikasikan visi dan misi sebuah brand, sekaligus menjadi salah satu komposisi penting dalam mengenalkan brand agar selalu menjadi pilihan utama konsumen (Wheeler, $2006:$ 19).

Selain masalah identitas visual, kendala lain yang dihadapi Teluk Youtefa adalah masalah sign system sebagai media informasi, pembuatan sign system yang baik adalah harus memenuhi 4 (empat) kriteria: mudah dilihat, mudah dibaca, mudah dimengerti dan dapat dipercaya. Dalam penempatan dan pembuatannya, sign system harus mudah diakses oleh orang, memiliki tingkat keterbacaan yang baik, dapat dipahami dengan benar dan informasinya tidak menyesatkan (Sumbo Tinarbuko,2012:13).

Namun hingga kini Teluk Youtefa belum memenuhi standar tersebut. Hal itu dapat terlihat dari keterbacaan signage atau papan penunjuk arah yang rendah, sulit dimengerti, tidak strategis serta tidak ada informasi tentang wisata ini.

Dengan adanya Identitas Visual maka akan lebih mudah jika ingin mengadakan festivalfestival dan sebagai media promosi teluk youtefa kedepannya, serta untuk mencapai itu, maka pihaknya akan memulai dari pengelolaan sarana dan prasarana objek wisata untuk menjadi daya tarik wisatawan (Mano,2019). Disisi lain, pihaknya akan melanjutkan tugas yang diberikan Walikota yakni, dalam 3 bulan ke depan akan 
lakukan pemetaan dan juga mulai mengidentifikasi masalah kurangnya daya tarik wisata yang ada di Kota Jayapura (Mano,2019).

"Tempatnya indah dan karena berbentuk teluk yang tidak begitu besar dan pasir yang putih bersih, kesanapun agak sulit karena banyaknya pemalak disekitar jalan mau ke daerah teluk, terlalu banyak biaya karena kurangnya keamanan" (Rahmat, Google Maps, 2019). "Perlu ada penanganan dari pemerintah karena dermaga tidak terurus dan identitas dari teluk kurang terlihat, padahal tempatnya bagus dan indah" (Otto, Google Maps, 2019).

Berdasarkan permasalahan di atas maka perlu dilakukan pembentukan identitas Teluk Youtefa. Identitas visual yang mengedepankan unsur komunikatif, modern dan terintegrasi sesuai dengan citra Teluk Youtefa diharapkan dapat memvisualisasikan potensi Teluk Youtefa sebagai objek wisata yang berkualitas. Dengan adanya perancangan identitas visual, Teluk Youtefa dapat mengakomodasi kebutuhan pengunjung akan informasi dan membangun kepercayaan pengunjung dalam hal kenyamanan berwisata. Hal tersebut juga dapat mendorong jumlah wisatawan yang datang dan berpotensi menjadikan Teluk Youtefa sebagai destinasi pilihan wisatawan.

$$
\text { Brand Destinasi dapat membantu }
$$
meningkatkan jumlah kunjungan wisatawan. Brand yang dilihat oleh wisatawan akan merangsang keputusan membeli dan akan membangun kedekatan antara wisatawan dan destinasi, sehingga dapat meningkatkan loyalitas wisatawan terhadap destinasi (Bungin, 2015: 5).

\section{METODE PENELITIAN}

Metode dan Teknik pengumpulan data yang digunakan dalam mengumpulkan data yang sesuai adalah: Wawancara dilakukan bersama narasumber Mathias Benoni Mano selaku Kepala Dinas Kebudayaan dan Priwisata Kota Jayapura, di Dinas Pariwisata Kota Jayapura. Aktivitas wawancara dilakukan dengan tatap muka secara langsung dan data ini kemudian akan dianalisis untuk membantu proses Perancangan Identitas Visual Destinasi Wisata Kawasan Teluk Youtefa Kota Jayapura.

Pada Proses ini dilakukan untuk mendapatkan data berkaitan dengan Perancangan Identitas Visual Destinasi Wisata Kawasan Teluk Youtefa Kota Jayapura. Dengan mengumpulkan data dari buku-buku atau internet, data yang diperoleh ini akan menjadi data sekunder yang mendukung data hasil observasi lapangan.
Adapun materi yang akan dijadikan kata kunci dalam mencari referensi adalah sebagai berikut:, Logo, Brand/Merek, Branding, Brand Awareness, Identitas Visual, Pariwisata, Brand Destinasi, Wisata Bahari, Semiotika, Teluk Youtefa dan Jayapura.

Observasi, tujuan Umum melakukan observasi lapangan adalah mengamati secara langsung di alam terbuka untuk mencari suatu kebenaran tentang sesuatu yang ingin dicocokkan dengan nalar pikiran manusia sehingga dapat dipertanggung jawabkan dan menjadikan kebenaran itu suatu fakta dan benar. Kegiatan pengamatan dilakukan guna menggali dan mengumpulkan data yang diperlukan bagi topik pembahasan guna pengembangan wawasan. Pengumpulan data dengan observasi lapangan dalam Perancangan Identitas Visual Destinasi Wisata Kawasan Teluk Youtefa Kota Jayapura yaitu dengan melakukan pengamatan langsung untuk memperoleh berbagai data konkret.

Destinasi wisata yang akan didatangi diantaranya:

1. Dinas Kebudayaan dan Pariwisata Kota Jayapura

2. Kawasan Teluk Youtefa

Dalam Teknik yang digunakan untuk menganalisis data adalah Kualitatif. Teknik ini digunakan untuk menganalisis data secara mendalam untuk selanjutnya dijadikan dasar perancangan brand destinasi. Adapun data yang dianalisis denga metode ini selain wawancara, kepustakaan dan observasi adalah Kawasan Teluk Youtefa di Kota Jayapura.

Metode analisis data yang digunakan dalam perancangan ini adalah deskriptif kualitatif dengan menggunakan metode analisis $5 \mathrm{~W}+1 \mathrm{H}$, yaitu: Who, What, Where, When, Why dan How. Problematika yang dibahas meliputi:

1. What?

a. Apa itu Kawasan Teluk Youtefa?

b. Apa saja fasilitas yang ditawarkan Kawasan Teluk Youtefa?

c. Apakah identitas visual Kawasan Teluk Youtefa sudah sesuai dengan citra Kawasan Teluk Youtefa?

2. Who?

a. Siapa yang bertanggung jawab dalam mengelola identitas visual Kawasan Teluk Youtefa, sehingga belum konsisten dan sesuai dengan citra Kawasan Teluk Youtefa?

b. Siapa pengunjung objek wisata Kawasan Teluk Youtefa? 
3. Where?

a. Dimana letak objek wisata Kawasan Teluk Youtefa?

b. Dimana saja lokasi peletakan sign system yang ada di Kawasan Teluk Youtefa?

4. When?

Sejak kapan Kawasan Teluk Youtefa dibuka sebagai objek wisata?

5. Why?

$$
\begin{aligned}
& \text { Mengapa Kawasan Teluk Youtefa } \\
& \text { membutuhkan perancangan identitas } \\
& \text { visual? }
\end{aligned}
$$

6. How?

a. Bagaimana sejarah berdirinya Kawasan Teluk Youtefa?

b. Bagaimana tanggapan masyarakat tentang Kawasan Teluk Youtefa?

Metode analisis STP terdiri dari segmentasi (Segmentation), target (Targeting), dan posisi (Positioning). Fungsinya untuk membantu menentukan target audiens serta pasar yang sesuai.

\section{HASIL DAN PEMBAHASAN Konsep Desain}

Konsep desain yang digunakan dalam Perancanan Identitas Visual Destinasi Wisata Kawasan Teluk Youtefa adalah Sesuai dengan identitas yang dibangun dan ingin ditonjolkan, citra yang ingin ditampilkan secara visual bahwa Kawasan Teluk Youtefa merupakan tempat wisata menyenangkan yang memperkenalkan budaya, sejarah dan keindahan alam kepada para wisatawannya. Oleh karena itu identitas visual di desain agar memiliki kesan menyenangkan, dan tidak terlepas dari unsur alam dan budaya suku tobati dan enggros. Kesan menyenangkan digunakan karena identik dengan karakter sebuah objek wisata yang merupakan tempat untuk bersenang-senang dan refreshing. Kemudian digunakan visual unsur alam dan budaya karena hal tersebut merupakan identitas utama yang ingin di tonjolkan dari Kawasan Teluk Youtefa.

\section{Media Utama \\ Graphic Standard Manual}

Graphic standard manual adalah buku panduan yang berisi aturan serta penggunaan identitas visual Youtefa dan mencakup logo, warna, tipografi, juga penerapannya pada media. Dengan bantuan graphic standard manual, identitas visual Youtefa dapat diterapkan oleh siapa saja dengan baik dan sesuai aturan. Media ini akan memiliki bentuk buku fisik dan digital. Graphic standard manual diberikan kepada pihak yang membutuhkan pedoman penggunaan identitas visual Youtefa, seperti desainer, percetakan, tim advertising, dan lainnya.

\section{Bahan:}

$\begin{array}{ll}\text { Sampul } & : \text { Kingstruk } \\ \text { Isi } & : \text { Kingstruk }\end{array}$

Ketebalan :

Sampul : $260 \mathrm{gsm}$

Isi $\quad: 150 \mathrm{gsm}$

Ukuran : $21 \times 14,85 \mathrm{~cm}$ (A5)

Teknik Cetak : Digital Printing

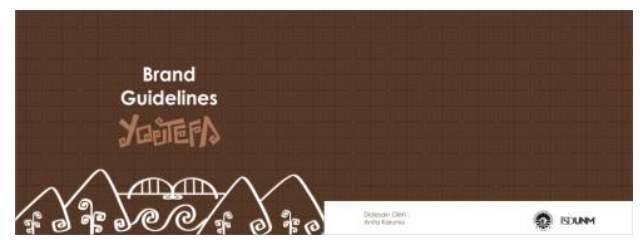

Gambar 3. 1 graphic standard manual Sampul (Sumber : Anita Karunia, 2019)

Desain dari halaman sampul ini dengan menggunakan layout horisontal di bagian sisi kiri adalah sampul depan dengan konsep latar desain mengunakan pattern dari Identitas Visual Youtefa, dan menggunakan dominan warna coklat yang dekat dengan kesan tradisi dan budaya sesuai dengan corporate color dan degan menggunakan motif atau icon dan landmark yang ada di teluk youtefa yaitu berupa gunung, jembatan youtefa, pantai, dan hutan mangrove, serta judulnya "Brand Guidelines Youtefa" tulisan Brand Guidlines menggunkan font Century Gothic dan tulisan Youtefa menggunakan typeface dari logo youtefa, dengan menggunakan tipografi dari font youtefa itu sendiri sebagai Identitas Visual.

Di bagian kanan adalah sampul belakang dengan menggunakan motif pattern dan menggunakan warna dominan coklat dan sentuhan warna putih untuk latar nama desain menggunakan font century gothic dan logo FSD dan UNM.

\section{Brand Guidelines}
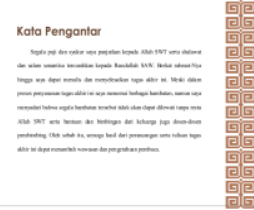

Gambar 3. 2 Isi graphic standard manual halaman 1-2 (Sumber : Anita Karunia, 2019) 


\section{Stationery}

Amplop

Bahan : HVS / Art Paper

Ketealan : 100-15gsm

Ukuran Pola : 27 x $24 \mathrm{~cm}$

Ukuran Amplop Lipat : 22x $11 \mathrm{~cm}$

Teknik Cetak : Digital Printing

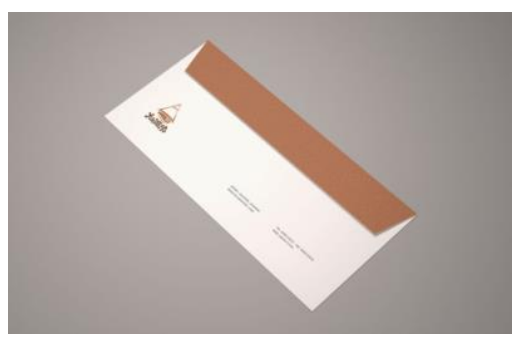

Gambar 3.3 Mockup Amplop (Sumber : Anita Karuina, 2019)
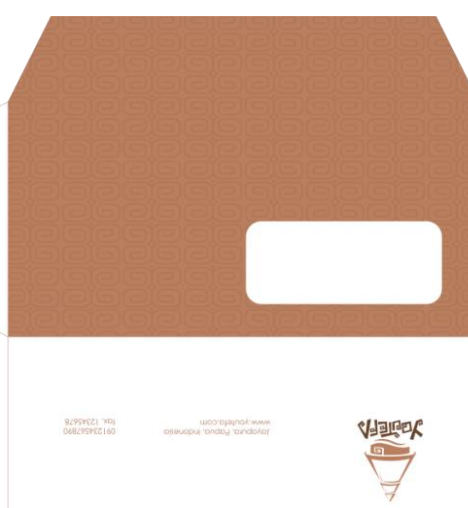

Gambar 3.4 Desain Amplop

(Sumber : Dokumentasi Pribadi, 2019)

\section{Kertas Surat}

Bahan : HVS

Ketebalan : 70gsm

Ukuran Pola : 27 x $29.7 \mathrm{~cm}$ (A4)

Teknik Cetak : Digital Printing

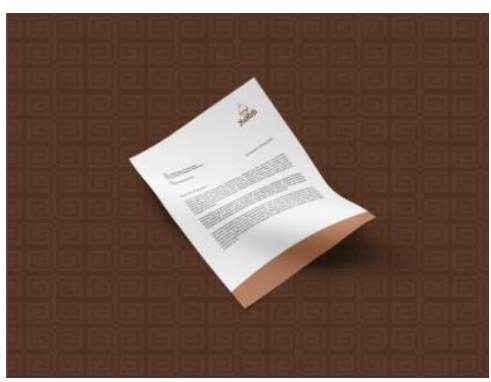

Gambar 3.4 Mockup Surat (Sumber : Anita Karuina, 2019)

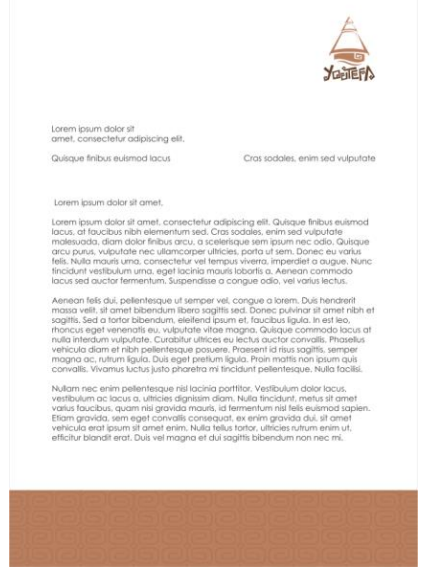

Gambar 3.5 Desain Surat (Sumber : Anita Karuina, 2019)

\section{Tanda Pengenal}

Bahan : PVC

Ukuran : 5.4 x $8.6 \mathrm{~cm}$

Teknik Cetak : Digital Printing

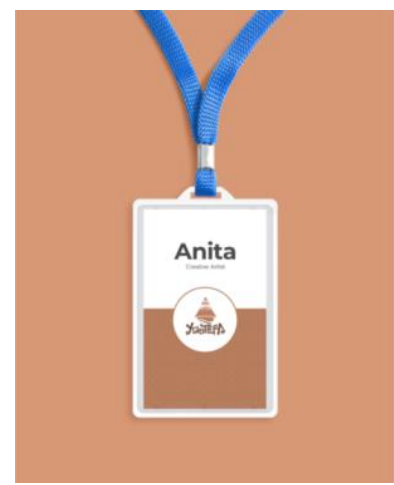

Gambar 3.6 Mockup Tanda Pengenal (Sumber : Anita Karuina, 2019)

\section{Stempel}

Jenis : Stempel Runaflek/ stempel flash Diameter : $3 \mathrm{~cm}$

Warna tinta : Coklat

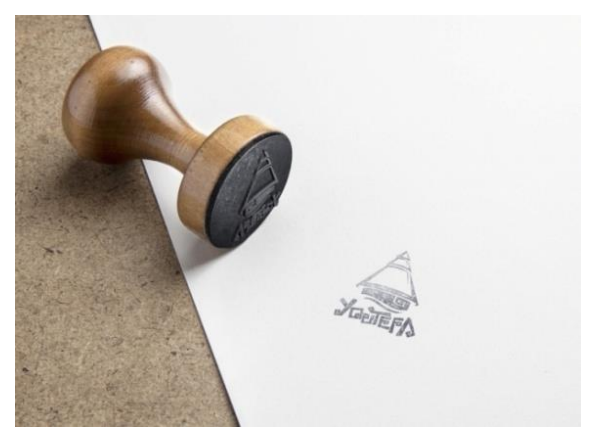

Gambar 3.7 Mockup Stempel (Sumber : Anita Karuina, 2019) 


\section{Merchandise \\ T-Shirt}

Bahan : Katun combed

Teknik cetak : manual sablon

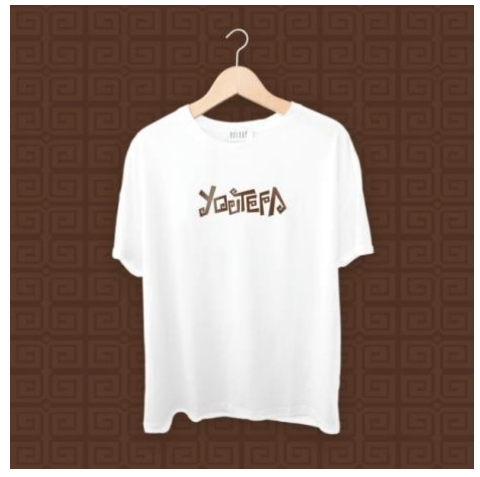

Gambar 3.8 Mockup T-Shirt model 1 (Sumber : Anita Karuina, 2019)

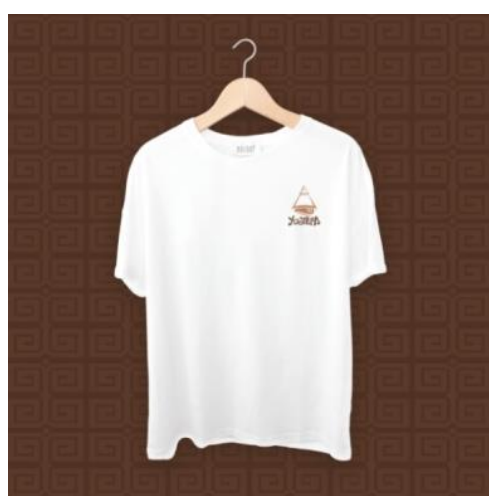

Gambar 3.9 Mockup T-Shirt model 2 (Sumber : Anita Karuina, 2019)

\section{Totebag}

Ukuran: 30x40cm

Bahan: Semi Kanvas

Teknik Cetak : Digital Printing

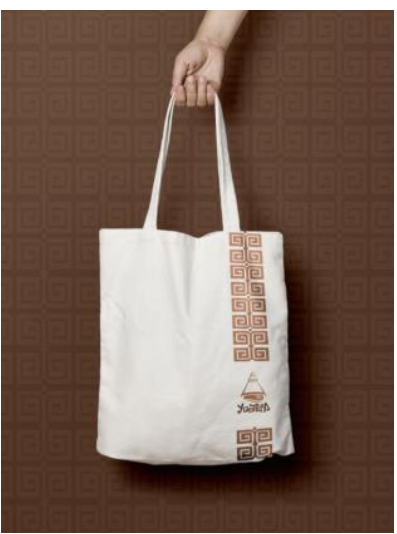

Gambar 5. 3 Mockup Totebag (Sumber : Anita Karuina, 2019)

\section{Gantungan Kunci}

Ukuran : 6 × $6 \mathrm{~cm}$

Bahan : Alumunium

Teknik Cetak : Digital Print

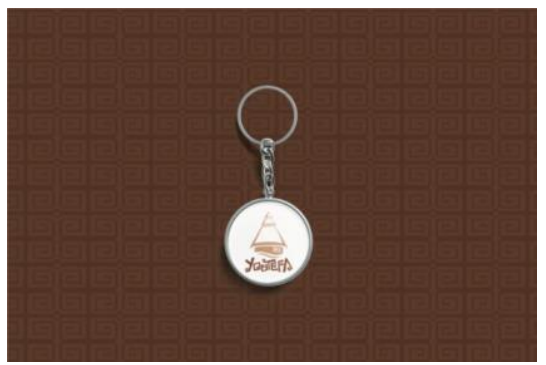

Gambar 5. 4 Mockup Gantungan Kunci (Sumber : Anita Karuina, 2019)

\section{Stiker}

Bahan : Kertas Sticker

Ukuran : a5

Teknik Cetak : Digital Print

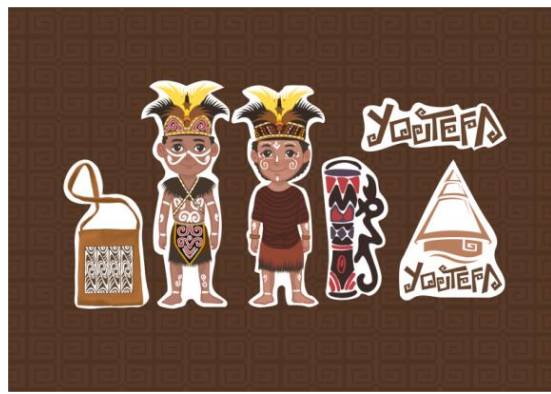

Gambar 5. 5 Sticker Pack Youtefa (Sumber : Anita Karuina, 2019)

\section{Postcard}

Bahan : Kertas Sticker

Ukuran : a5

Teknik Cetak : Digital Print

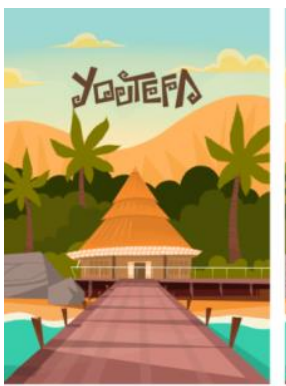

depan

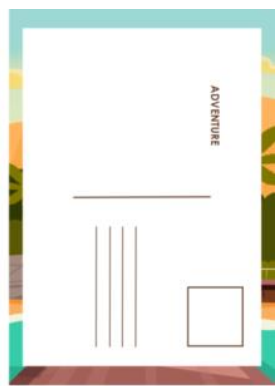

belakang
Gambar 5. 6 Sticker Pack Youtefa (Sumber : Anita Karuina, 2019) 


\section{Poster}

Bahan : Kingstruk 260

Ukuran 4 x 6 inci

Teknik cetak : Digital Print

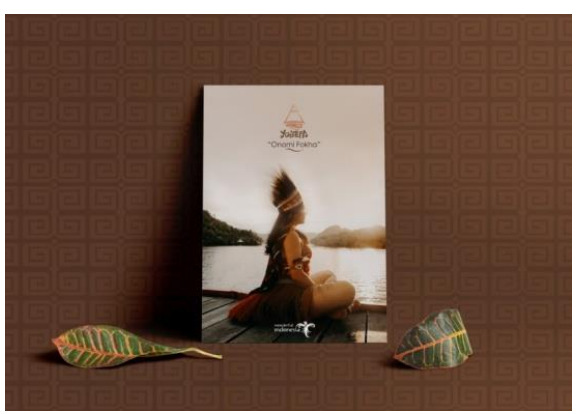

Gambar 5. 7 Desain Postcard Youtefa (Sumber : Anita Karuina, 2019)

\section{X-Banner}

\section{Bahan : Albatros \\ Ukuran : $160 \times 60 \mathrm{~cm}$ \\ Teknik Cetak : Digital Printing}

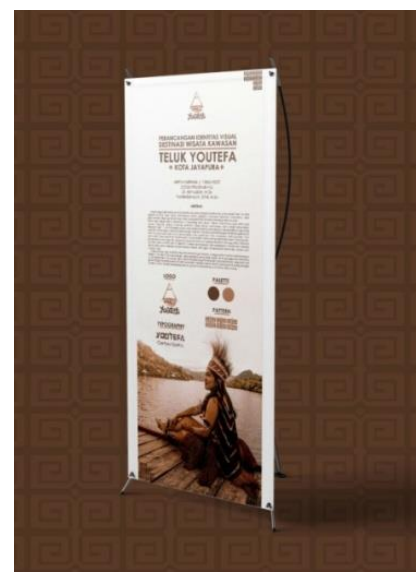

Gambar 5. 8 Desain X-Banner

(Sumber : Anita Karuina, 2019)

\section{KESIMPULAN DAN SARAN Kesimpulan}

Kawasan Teluk Youtefa memiliki pemandangan alam yang indah yang terdiri dari hamparan hijau hutan mangrove dan hutan sagu serta hamparan biru air laut Teluk Youtefa dengan dua pulau cantik yang terletak di tengahnya, yakni Pulau Tobati dan Engros. Selain itu juga terdapat Lapangan Timbul Tenggelam. Disebut lapangan timbul tenggelam karena lapangan ini hanya akan nampak jika air sedang surut dan hilang jika air sedang pasang.
Konsep wisata dengan menggabungkan unsur budaya, sejarah dan hiburan dan alam membuat tempat wisata ini memiliki potensi yang tinggi sebagai destinasi wisata di Kota Jayapura, dan harganya yang terjangkau juga membuat tempat wisata ini sangat cocok untuk dijadikan pilihan berekreasi bersama keluarga untuk refreshing.

Oleh sebab itu, perancangan ini dilakukan sebagai solusi atas permasalahan yang dimiliki oleh Kawasan Teluk Youtefa. Perancangan ini merupakan proses identitas visual Youtefa melalui logo baru. Hasil dari perancangan ini berupa buku panduan logo yang berisi logogram, typeface, pattern dan supergraphic. Solusi ini menjadi cara yang tepat untuk memberikan wajah baru bagi pariwisata. Selain itu, mempermudah identifikasi dan mengkomunikasikan pesan kepada pelanggan. Logo sebagai identitas visual baru Youtefa akan didukung dengan penerapannya pada media komunikasi seperti stationery dan gifts/merchandise.Hasil perancangan ini diharapkan dapat memberikan pengaruh positif terhadap kawasan teluk youtefa, sehingga identitas visual usaha dapat lebih dikenali, menjadi pembeda dengan kompetitornya, meningkatkan brand awareness, dan membawa keuntungan bagi pariwisata. Keseluruhan hasil desain perancangan identitas visual Kawasan Teluk Youtefa ini dirancang untuk memberikan image tersendiri bagi Kawasan Teluk Youtefa, baik melalui bentuk logo, penggunaan warna dan tipografi, maupun aspek desain lainnya. Sehingga pariwisata dapat dibedakan dengan kompetitornya dan memiliki identitasnya sendiri.

\section{SARAN}

Perancangan identitas visual destinasi wisata kawasan teluk youtefa ini masih memiliki kekurangan dan perlu untuk dikembangkan. Pengembangan tersebut dapat dilakukan terhadap media komunikasi yang digunakan. Seperti mengembangkan media komunikasi menjadi media promosi agar penyampaian pesan dan brand dapat lebih tersampaikan. Misalnya,

1. Memanfaatkan social media dan website untuk memasarkan jasa yang ditawarkan perusahaan serta mengiklankannya kepada masyarakat umum.

2. Penggunaan media komunikasi ini harus dilakukan secara terus menerus agar identitas Kawasan Teluk Youtefa yang sudah dirancang tidak sia-sia. 


\section{DAFTAR PUSTAKA}

Bara, A. P. 2017. Perancangan Brand Identity Home Spa Laksmi Sebagai Upaya Meningkatkan Brand Awareness .

Bungin, Burhan. (2015). Komunikasi Pariwisata (Pemasaran Dan Brand Destinasi). Cetakan ke-1. Jakarta: Prenadamedia Group.

Masdalia, L. 2018. In S. D. Jayapura. Jayapura: Badan Pusat Statistik Kota Jayapura.

Papua, W. (2016). Wisata Alam Teluk Youtefa. Retrieved Oktober 18, 2019, from Wisata Papua: http://www.wisatapapua.com/2014/03/wisat a-taman-wisata-alam-teluk-youtefa.html

Tanuatmadja, Y., Swandi, I. W., \& Raditya, A. 2014. Perancangan Branding "Marilyn's Cake" Surabaya.

Tinarbuko, Sumbo. (2012). Semiotika Komunikasi Visual. Yogyakarta: Jalasutra.

Wheeler, Alina. (2013). Designing Brand Identity: An essential guide for the whole branding team. New Jersey: John Wiley \& Sons, Inc.

Wheeler, Alina. (2006). Designing Brand Identity: A Complete Guide to Creating, Building, and Maintaining Strong Brands. New Jersey: John Wiley \& Sons, Inc.

Wheeler, A. 2009. Designing Brand Identity. New Jersey: John Wiley \& Sons. 